Editorial

\title{
The Ongoing Transformation of the Digital Public Sphere: Basic Considerations on a Moving Target
}

\author{
Emiliana De Blasio ${ }^{1}$, Marianne Kneuer, ${ }^{2}$ Wolf J. Schünemann ${ }^{2}$ and Michele Sorice ${ }^{*, 1}$ \\ ${ }^{1}$ Centre for Conflict and Participation Studies, LUISS University, 00197 Rome, Italy; E-Mails: edeblasio@luiss.it (E.D.B.), \\ msorice@luiss.it (M.S.) \\ 2 Institute of Social Sciences, University of Hildesheim, 31141 Hildesheim, Germany; \\ E-Mails: kneuer@uni-hildesheim.de (M.K.),wolf.schuenemann@uni-hildesheim.de (W.J.S.) \\ * Corresponding author
}

Submitted: 8 September 2020 | Published: 8 October 2020

\begin{abstract}
The recent decades more than anything else have revealed the ambivalence not only of the articulated expectations about the digital public sphere but also of the 'real' development itself. This thematic issue of Media and Communication highlights some of the criticalities and specificities of the evolution of the public sphere during this period where digital communication ecosystems are becoming increasingly central. The different articles offer a polyphonic perspective and thus contribute significantly to the debate on the transformations of the public sphere, which-in the time of the Covid-19 pandemic-dramatically affect the very essence of our democracy.
\end{abstract}

\section{Keywords}

crisis; democracy; digital ecosystems; digital media; platforms; politics; post-public sphere; public sphere

Issue

This editorial is part of the issue "The Ongoing Transformation of the Digital Public Sphere" edited by Emiliana De Blasio (LUISS University, Italy), Marianne Kneuer (Hildesheim University, Germany), Wolf J. Schünemann (Hildesheim University, Germany) and Michele Sorice (LUISS University, Italy).

(C) 2020 by the authors; licensee Cogitatio (Lisbon, Portugal). This article is licensed under a Creative Commons Attribution 4.0 International License (CC BY).

The emergence of digital media generated a whole array of euphoric expectations regarding the reconfiguration of the public sphere: One points to an emanating network society characterized by a de-hierarchized structure (Castells, 2011), and by a new autonomy from the 'institutional' power (Castells, 2012). Others emphasize the prospect of public debates being more inclusive, especially of those segments of the population that had been previously marginalized. Moreover, digitalization seems to entail the promise of greater transparency, inducing decision-makers to be more responsive and accountable. And finally, it has been claimed that digitalization will overcome the Westphalian political imaginary, in which the Habermasian theory of the public sphere is situated, leading to a transnational public sphere (Fraser, 2014). The recent decades more than anything else have re- vealed the ambivalence not only of the articulated expectations but also of the 'real' development itself. The vision of a transformed digital public sphere as a globally networked sphere, reconfigured in its power distribution and deterritorialized is challenged by the reality of a disintegrated public sphere shaped by cyber ghettos (Dahlgren, 2005), where public discourses are managed by algorithms, and geography still seems to count (Kneuer \& Datts, 2020).

Hence, the transformation of the digital public sphere confronts us with basic conceptual challenges as well as with a variety of empirical puzzles, and not least the methodological questions of how to tackle the subject of research.

One first important delineation concerns the concepts of the public sphere, public space, and public opin- 
ion which in the contemporary public debate are often confused. The concept of the public sphere refers to the discursive process through which the beliefs of public opinion are produced and legitimized: In essence, it primarily involves the communicative processes underlying the construction of opinion. Public space, on the other hand, can also exist without the public sphere, as in the case of the Internet or, more generally, without what are defined as mediated public spaces which tend to be framed in communicative ecosystems. The latter, therefore, become places of representation of politics and public discourse. The development of digital media has accelerated the process - active since the 1980s-of the dilution of the public sphere, which no longer runs out of public space since the latter also includes the 'peripheral' territories of civil society where interests, sensitivities, and issues are born and develop, sometimes distant from mainstream cultures. In these symbolic spaces (which often also offer themselves as physical 'territories' for comparison and debate), forms of civic engagement develop and legitimate or antagonistic or contesting instances of dominant cultures emerge.

A second aspect of the new public sphere refers to the digital platforms which have achieved increasing relevance for the dynamics of public opinion development. The process of "platformization" of contemporary societies (Jin, 2020; van Dijck, Poell, \& de Waal, 2018) has led to a transformation of the spaces of public debate. The centrality of platforms, which have become places of confrontation and conflict over matters of public opinion, has facilitated the emergence of the phenomena of information disorder, bringing traditional concepts of media studies such as 'manipulation' and 'influence' back into the public and academic debate. The elements that made the topic of manipulation re-emerge are to be found precisely in digital communication, which initially seemed to be the place for the subject's autonomy and freedom. The analysis of the role of digital political communication in the mechanisms of 'manipulation' and 'disinformation' exploded dramatically with the Facebook-Cambridge Analytica affair, in 2018, but the signs of this change in the climate of public opinion around the role of the media were already present beforehand with the emergence of the ambiguous concept of post-truth.

While the digitalization of the public sphere was initially praised as the possibility of disintermediation and of creating alternative spaces bypassing the gatekeepers of the 'classic' media channels, the uncontrolled opinions produced on or by 'social' platforms risk creating a space of manipulation, a territory in which-in Hannah Arendt's (1967) perspective-truth and politics are selfexcluding. Starting from this debate on the relationships between lies and politics, the theory of echo chambers also developed: Social media (and more generally digital ecosystems) would be closed and self-referential spaces, in which subjects engage in relationships only with those who think in the same way (or who have contiguous positions), effectively excluding any form of discursive hybridization and dialogue between different public spaces.

Recently, Colin Crouch (2019) noted that although regulatory institutions (from the courts to the media) continue to exist and function, decision making is now the preserve of narrow circles reserved for economic elites. This situation, which breaks the 'sentimental connection' between subjects and intermediate bodies (determining, moreover, the need for new forms of representation), favors populist political communication. Populist political communication can be considered a specific feature of post-democracy; according to Philip Schlesinger (2020) "if populism is a feature of postdemocracy, then in line with this, political communication under these conditions could be better classified as operating in a post-public sphere."

The post-public sphere is located at the intersection of various phenomena, characterized by the useunstable and by definition non-normative-of the prefix "post": 1) the post-representative trends discussed by John Keane (2013) which reveal the importance of digital communication ecosystems in the development processes of forms of occasional representation but also in the emergence of the apparent conceptual oxymoron of direct representation (De Blasio \& Sorice, 2020; Urbinati, 2020); 2) the development of the 'post-political' concept, however ambiguous and mostly connected to the processes of depoliticization; 3 ) the affirmation of a postdemocracy that makes the mechanisms of the commodification of citizenship its distinctive feature; and 4) the post-private era (Spivak, 2019) which implies increasingly blurred lines between public and private and which questions the basic idea of the public sphere as the inevitable and counterbalancing twin of privacy. In fact, this expansion of the private creates new trade-offs between the constant exposure to a publicness which can be categorized as a kind of absolute transparency and the loss of control over that which we want to (and should) share publicly, and that which we do not (Kneuer, 2020).

The transformation of the public sphere and the emergence of the notion of the post-public sphere intersect the development of platforms and, more generally, the process of platformization of the public sphere (Sorice, 2020). In essence, the 'platformized' post public sphere adopts the discursive modalities of neoliberalism, it is based on economic, political, and cultural power asymmetries that tend to fragment the public sphere, making it a space for legitimizing the 'single thought' instead of a place symbolic of discussion and debate. The platformized public sphere is not based on diversity (much less on its integration) but on the fragmentation of non-connected sub-publics.

This thematic issue of Media and Communication highlights some of the mentioned criticalities and specificities of the evolution of the public sphere during this period where digital communication ecosystems are becoming increasingly central. 
In their conceptual contribution, Sara Bentivegna and Giovanni Boccia Artieri (2020) introduce the notion of the interrelated public agenda as a frame to study an ever more fragmented public sphere. Their article provides evidence of three antinomies (horizontality vs verticality, personal vs aggregative, and dynamic vs static), which are suggested as being useful for the interpretation of the transformation of the digital public sphere.

The implications for political parties and representation are examined by Emiliana De Blasio and Lorenzo Viviani (2020), who present an important analysis on the relationship between the evolution of digital ecosystems and the way in which political organizations are structured. The authors studied digital platforms of political parties in four countries and their results highlight how the new forms of mobilization and aggregation have opened up different but interconnected public spaces.

Two articles focus on the critical question of how far we can speak of a transnational digital public sphere, both presenting rather sceptical findings. Jan Kermer and Rolf Nijmeijer (2020) focus on the transnationalization of the public sphere in Europe as a background for a greater sense of European belonging. The authors warn however that this should be conceived of as a linear relationship. The Internet has enabled new actors from outside Europe to easily infiltrate the Europeanized public sphere. Furthermore, cyberspace has shown itself to be a hotbed of Euroscepticism and polarized discourse.

The other article drawing on the transnational dimension studies the transnational quality of issue publics with the example of climate change on Twitter. The multimethod analysis by Wolf Schünemann (2020) finds that there is no simple correlation between digital media use, global concerns (such as climate change), and a transnationalized debate. Thus, what crystallizes is an effect of language structuring the discourse, as well as factors such as regional or developmental status which play a role.

Several contributions refer to the discourse and the quality of deliberation as an essential part of the digital public sphere. The echo chambers thesis is examined by Pere Masip, Jaume Suau, and Carlos Ruiz-Caballero (2020) who present empirical research on the Spanish case. Their findings show that Spanish citizens who are more active on social media are more likely to be exposed to news content from different ideological positions than those who are less active users. This is an interesting perspective to investigate the role of filter bubbles too.

Another relevant issue for digital deliberation is how far it instigates (or not) polarization. IgnacioJesús Serrano-Contreras, Javier García-Marín, and Óscar G. Luengo (2020) offer an important contribution to the analysis of the relationships between the instances of polarization and the triggering of the deliberation processes. They propose an index to measure the polarization of each comment posted on YouTube and to analyse the average polarization of comments for each video under analysis.
With populism being an increasingly relevant phenomenon, Mario Datts (2020) raises the issue of how strongly populist frames permeate public debates. He analyses the role of 'ordinary citizens' on Twitter during the Migration Compact Conference in Marrakesh. Somewhat against expectations, he finds that populist narratives did not dominate the Twitter debate on migration. However, the empirical results indicate that ordinary citizens play an important role in the creation and dissemination of populist content. Thus, it seems that the social web widens the public sphere, including those actors who do not communicate in accordance with the Habermasian conceptualization of it.

An analysis of the Hashtag Assemblage of \#metwo is proposed by Sebastian Berg, Tim König, and Ann-Kathrin Koster (2020). They are interested in hashtags as a specific tool of discursive fabrication, which also embody the active participation of the actors. Examining the hashtag \#metwo in Germany in the summer of 2018, they show the hashtag assemblage's heterogeneity and potential for subaltern agency. At the same time, they demonstrate how hashtag assemblages as epistemic practices are inherently dynamic.

Finally, the article of Andreu Casero-Ripolles, JosepLluís Micó-Sanz, and Míriam Díez-Bosch (2020) proves how the geographical location matters for the discourse. The authors analyzed Twitter communication on the negotiation process for the formation of the Spanish government in 2015 and 2016 in three Spanish cities (Madrid, Barcelona, and Valencia). The results show that there is a correlation between the geographical location of the users and the political conversation on Twitter, despite the presumption that the Twittersphere is de-territorialized.

In sum, the studies presented confirm the ambivalence of the digital public sphere topic. Moreover, they may even question the term 'digital' because-as many authors underline-the communicative processes continue to take place in a hybrid space. Regarding the methodology, this thematic issue stands out by offering diverse and innovative methods and approaches such as geolocation, topic modelling, network analysis etc., enriching social media research in general.

While this thematic issue was being prepared, the latest challenge for the public sphere emerged: the Covid-19 pandemic. Recently, Aeron Davis (2019) identified in the logic of the 'crisis,' the framework dimension of contemporary political communication, which moreover calls into question all the theories that emerged in the 1980s and 1990s. This scheme can be easily applied to the entire global communication ecosystem. The Covid-19 pandemic has further confirmed the transformation of communication processes, a substantial rearticulation of public opinion and a reshaping of the public sphere. New trends have emerged or established themselves while the critical issues arising from the exponential growth of information flow (information overload) have been confirmed. Beyond the dramatic health 
aspects, the Covid-19 pandemic has also shown the unprecedented ways in which public opinion has reacted, both to the sometimes-entropic flow of information (often, moreover, of a technical-scientific nature) and to the actions taken by public authorities to limit the contagion.

This thematic issue of Media and Communication contributes significantly to the debate on the transformations, which - in the time of the Covid-19 pandemicdramatically affect the very essence of our democracy.

\section{Acknowledgments}

We thank all the participants of the workshop on 'Transformations in the digital age' at the University of Hildesheim. For the workshop and publication, we received funding from the German Academic Exchange Service as part of the program 'University dialogue with Southern Europe.' We are particularly grateful to the anonymous reviewers that have helped to secure the academic quality of this thematic issue.

\section{Conflict of Interests}

The authors declare no conflict of interests.

\section{References}

Arendt, H. (1967, February 25). Truth and politics. The New Yorker.

Bentivegna, S., \& Artieri, G. B. (2020). Rethinking public agenda in a time of high-choice media environment. Media and Communication, 8(4), 6-15.

Berg, S., König, T., \& Koster, A.-K. (2020). Political opinion formation as epistemic practice: The hashtag assemblage of \#metwo. Media and Communication, 8(4), 84-95.

Casero-Ripollés, A., Micó-Sanz, J.-L., \& Díez-Bosch, M. (2020). Digital public sphere and geography: The influence of physical location on Twitter's political conversation. Media and Communication, 8(4), 96-106.

Castells, M. (2011). Communication power. Oxford: Oxford University Press.

Castells, M. (2012). Networks of outrage and hope: Social movements in the internet age. Cambridge: Polity Press.

Crouch, C. (2019). Post-democracy and populism. The Political Quarterly, 90(1), 124-137.

Dahlgren, P. (2005). The Internet, public spheres, and political communication: Dispersion and deliberation. Political Communication, 22(2), 147-162.

Datts, M. (2020). Social media, populism, and migration. Media and Communication, 8(4), 73-83.

Davis, A. (2019). Political communication: A new introduction for crisis times. Cambridge: Polity.

De Blasio, E., \& Sorice, M. (2020). Technopopulism and direct representation. In P. Blokker and M. Anselmi
(Eds.), Multiple populisms: Italy as democracy's mirror. London: Routledge.

De Blasio, E., \& Viviani, L. (2020). Platform party between digital activism and hyper-leadership: The reshaping of the public sphere. Media and Communication, 8(4), 16-27.

Fraser, N. (2014). Transnationalizing the public sphere: On the legitimacy and efficacy of public opinion in a post-Westphalian world. In N. Fraser (Ed.), Transnationalizing the public sphere (pp. 8-43). Cambridge: Polity.

Jin, D. Y. (2020). Globalization and media in the digital platform age. London: Routledge.

Keane, J. (2013). Democracy and media decadence. Cambridge: Cambridge University Press.

Kermer, J. E., \& Nijmeijer, R. A. (2020). Identity and Europeanised public spheres in the context of social media and information disorder. Media and Communication, 8(4), 28-39.

Kneuer, M. (2020). Entre la luz estridente de la publicaidad y la sombra protectora: La esfera pública bajo las condiciones de digitalidad [Between the dazzling light of publicity and the protecting shadow: The public sphere under the conditions of digitality]. Sistema: Revista de Ciencias Sociales, 257, 3-19.

Kneuer, M., \& Datts, M. (2020). E-democracy and the matter of scale: Revisiting the democratic promises of the Internet in terms of the spatial dimension. Politische Viertelsjahreschrift, 61(2), 285-308. https:// doi.org/10.1007/s11615-020-00250-6

Masip, P., Suau, J., \& Ruiz-Caballero, C. (2020). Incidental exposure to non-like-minded news through social media: Opposing voices in echo-chambers' news feeds. Media and Communication, 8(4), 53-62.

Schlesinger, P. (2020). After the post-public sphere? Media Culture and Society. Advance online publication. https://doi.org/10.1177\%2F0163443720948003

Schünemann, W. J. (2020). Ready for the world? Measuring the (trans-)national quality of political issue publics on Twitter. Media and Communication, 8(4), 40-52.

Serrano-Contreras, I.-J., García-Marín, J., Luengo, Ó., G. (2020). Measuring online political dialogue: Does polarization trigger more deliberation? Media and Communication, 8(4), 63-72.

Sorice, M. (2020). La piattaformizzazione della sfera pubblica [The platformization of the public sphere]. Comunicazione Politica, XXI.

Spivak, N. (2019). Post-privacy world. Wired. https:// www.wired.com/insights/2013/07/the-post-privacyworld

Urbinati, N. (2020). lo, il popolo [I, the people]. Milano: Feltrinelli.

van Dijck, J., Poell, T., \& de Waal, M. (2018). Platform society: Public values in a connective world. Oxford: Oxford University Press. 


\section{About the Authors}

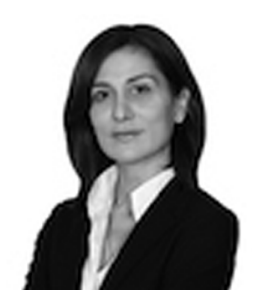

Emiliana De Blasio teaches Media Sociology, Gender Politics and Open Government at the Department of Political Sciences of LUISS University of Rome, Italy. She is the Deputy Director of the LUISS Centre for Conflict and Participation Studies and Invited Professor at Gregorian University. Her research activities focus on the digital ecosystem, the transformation of the public sphere, the relationship between gender and party organization, e-democracy, open government, and the impact of technologies on populisms.

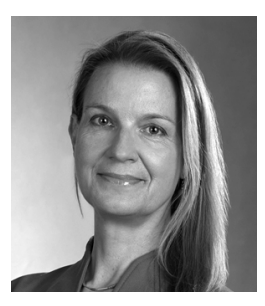

Marianne Kneuer is Professor for Comparative Politics and International Relations at the University of Hildesheim. She co-founded the Center of Digital Change at this university and serves on its board. Her research focus on quality of democracy as well as e-participation, e-government, and social media interaction in democracies and autocracies. Currently, she conducts two projects on citizens' communication (online and offline) in times of crises.

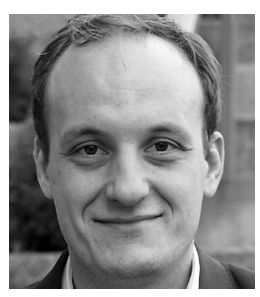

Wolf J. Schünemann is Assistant Professor at Hildesheim University with a focus on Internet and Politics. He has published on online communication, internet governance, and European integration in the International Review of Information Ethics, New Media and Society, and the Journal of European Integration.

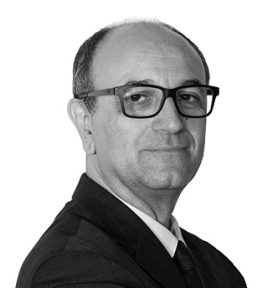

Michele Sorice is Professor of Political Sociology, Media Studies, and Democratic Innovations at LUISS University. He is the Director of the Centre for Conflict and Participation Studies. His main research interests focus on political communication, digital ecosystems, and political participation, in the frame of the critical media studies. Currently, he participates to two projects on populism and authoritarianism. 